\title{
SISTEM KEAMANAN PADA RUANGAN PRIBADI MENGGUNAKAN MIKROKONTROLER ARDUINO DAN SMS GATEWAY
}

\author{
Rahmad Genaldo*,1), Tri Septyawan²), Ade Surahman), Purwono Prasetyawan') \\ ${ }^{1,2,3)}$ Program Studi Teknik Komputer, Fakultas Teknik dan Ilmu Komputer, Universitas Teknokrat Indonesia \\ Jl. ZA. Pagar Alam No.9 -11, Labuhan Ratu, Bandar Lampung, Indonesia 35132 \\ 4) Program Studi Teknik Elektro, Fakultas Teknik dan Ilmu Komputer, Universitas Teknokrat Indonesia \\ Jl. ZA. Pagar Alam No.9 -11, Labuhan Ratu, Bandar Lampung, Indonesia 35132
}

Email: ${ }^{1}$ rahmadgenaldo@teknokrat.ac.id

\begin{abstract}
Making this tool aims to improve the security system in a private room in order to reduce the loss rate of valuables in the room. So a tool called security system in private room with Arduino microcontroller and SMS gateway is designed to inform the owner of the room when the room owner is not in the room via an SMS gateway that someone has entered the room without the knowledge of the room owner. The designed system consists of several parts, namely: power supply, control system, mechanical circuit and programs. The power supply is a source of power to run the entire system consisting of voltage. The control system is an electronic circuit designed in such a way that it can function as a data processor with a microcontroller as the control center. The next part is a series of mechanics that functions to regulate the opening and closing of a door in the room. The last part is a program that functions to adjust the microcontroller so that it can work in accordance with the features being worked on.
\end{abstract}

Keywords: Arduino, security system, SMS gateway

\section{Abstrak}

Pembuatan alat ini bertujuan untuk meningkatkan sistem keamanan pada sebuah ruangan pribadi agar dapat mengurangi tingkat kehilangan barang-barang berharga yang ada didalam ruangan tersebut. Maka dirancang sebuah alat yang berjudul sistem keamanan pada ruangan pribadi dengan mikrokontroler Arduino dan SMS gateway yang bertujuan memberitahu kepada pemilik ruangan pada saat pemilik ruangan tidak ada didalam ruangan melalui sms gateway bahwa ada seseorang yang memasuki ruangan tanpa sepengetahuan si pemilik ruangan. Sistem yang dirancang terdiri dari beberapa bagian yaitu: catu daya, system kontrol, rangkaian mekanika dan program. Catu daya merupakan sumber daya untuk menjalankan seluruh sistem yang terdiri dari tegangan. Sistem kendali berupa rangkaian elektronik yang didesain sedemikian rupa sehingga dapat berfungsi sebagai pengolah data dengan mikrokontroller sebagai pusat kendali. Bagian selanjutnya adalah rangkaian mekanika yang berfungsi untuk mengatur buka tutup pada sebuah pintu di ruangan. Bagian terakhir adalah program yang berfungsi untuk mengatur mikrokontroler sehingga dapat bekerja sesuai dengan fitur yang dikerjakan.

Kata Kunci: Arduino, sistem keamanan, SMS gateway

\section{Pendahuluan}

Keamanan merupakan salah satu hal yang penting dalam kehidupan [1], setiap manusia membutuhkan jaminan keamanan yang lebih pada tempat tinggal mereka. Seperti halnya kesehatan, keamanan merupakan suatu aspek yang penting dalam kehidupan. Karena itulah berbagai macam pengembangan dilakukan untuk memberikan keamanan dengan memanfaatkan kemajuan teknologi yang mempermudah berbagai pekerjaan manusia [2][3][4], bahkan melindungi aset yang dimiliki, sehingga diharapkan dengan pengaplikasian sistem keamanan dapat memberikan rasa aman dan nyaman.

Selain hal tersebut tentunya dengan pengaplikasian sistem keamanan yang akan dirancang ini kiranya dapat menekan angka kriminalitas yang terjadi di masyarakat khususnya tindak kejahatan pencurian. Karena mobilitas manusia yang semakin cepat akibat dari aktifitas yang mereka lakukan di era globalisasi sekarang ini menjadikan mereka memerlukan sebuah teknologi keamanan yang mempunyai ciri mobile technology, yaitu dalam mendapatkan informasi ataupun pengaksesannya menggunakan cara yang mudah, cepat dan tidak mengganggu aktifitas mereka. Contoh dari mobile technology ialah ditemukannya teknologi handphone yang sesuai dengan kebutuhan manusia, yaitu mampu berkomunikasi jarak jauh dimanapun mereka berada salah satunya adalah melalui SMS (Short Message Service).

Pada penelitian sebelumnya, telah dikembangkan sistem keamanan menggunakan sensor PIR (Passive Infrared) yang berbasis mikrokontroler AT89S52 untuk sistem keamanan suatu ruang [5]. Keluaran dari alat ini adalah berupa alarm yang digunakan untuk peringatan bahwa suatu ruang yang telah dilengkapi dengan sensor ini telah dimasuki oleh seseorang. Penelitian tersebut menggunakan satu buah sensor yang telah terpasang ke motor stepper. Motor stepper selalu bergerak untuk mencari dan mendeteksi keberadaan manusia. 
Mikrokontroler akan menghentikan gerakannya jika sensor mendeteksi sebuah gangguan. Penggunaan sensor inframerah pasif untuk mendeteksi gerakan tiga orang lanjut usia di sebuah panti wreda [6]. Dalam penelitian tersebut berhasil dideteksi kegiatan manula setiap hari selama tujuh hari. Hal ini bertujuan untuk mengetahui pola hidup mereka. Pemasangan sensor diletakkan di langitlangit rumah tersebut. Karena dengan fasilitas inilah seseorang dapat mengirimkan pesan ketujuan secara cepat, tepat dan biaya yang murah.

Penelitian ini bertujuan merancang suatu sistem keamanan rumah yang terdiri dari sensor PIR sebagai sensor untuk mendeteksi pencuri. Sensor Magnet sebagai indikator pintu atau jendela apakah pintu atau jendela sedang ditutup atau terbuka, mikrokontroller arduino UNO sebagai proses atau otak dari alat dan SIM 800L sebagai transmiter pesan notifikasi kepada pemilik rumah yang berupa sms berbasis mikrokontroler, sehingga dapat benar-benar membantu seseorang baik mengenai efisiensi biaya dan waktu dalam memonitoring keadaan rumah.

\section{Metode}

\section{A. Alat}

Dalam penelitian ini, terdapat enam komponen elektronika utama yang digunakan, yakni sebagai berikut:

1. Arduino UNO, board mikrokontroler berbasis ATmega328 (datasheet) [7][8]. Memiliki 14 pin input dari output digital dimana 6 pin input tersebut dapat digunakan sebagai output PWM dan 6 pin input analog, $16 \mathrm{MHz}$ osilator kristal, koneksi USB, jack power, ICSP header, dan tombol reset. Untuk mendukung mikrokontroler agar dapat digunakan, cukup hanya menghubungkan Board Arduino UNO ke komputer dengan menggunakan kabel USB atau listrik dengan AC yang ke adaptor DC atau baterai untuk menjalankannya. Arduino UNO dapat dilihat pada Gambar 1.

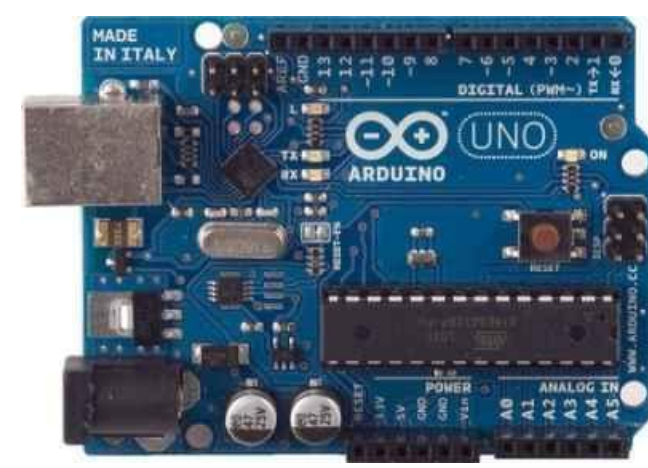

Gambar 1. Arduino UNO

2. Sensor PIR, memungkinkan untuk mendeteksi adanya gerakan, digunakan untuk mendeteksi apakah manusia/benda telah bergerak atau keluar dari jangkauan sensor. PIR pada dasarnya terbuat dari sensor piroelektrik yang dapat mendeteksi tingkat radiasi inframerah. Sensor PIR memancarkan sejumlah radiasi tingkat rendah, dan panas. Sensor dalam pendeteksi gerak sebenarnya terbagi dalam dua bagian untuk mendeteksi gerakan (perubahan). Kedua bagian ini berkabel sehingga mereka dapat berhubungan satu sama lain. Jika salah satu mendeteksi radiasi Infrared dari yang lainnya, maka menghasilkan output yang bernilai High atau Low. Sensor PIR motion yang digunakan ditunjukkan pada Gambar 2.

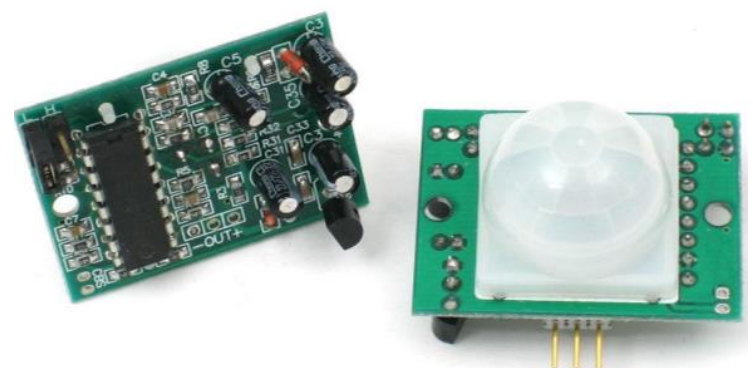

Gambar 2. Sensor PIR motion

3. Buzzer, digunakan untuk memunculkan nada tunggal berdasarkan pulsa frekuensi yang diberikan baik itu digital/analog [9]. Buzzer dapat dilihat pada Gambar 3.

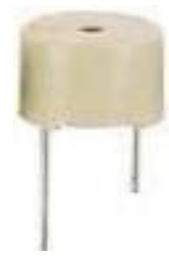

Gambar 3. Buzzer

4. Sensor Magnet, disebut juga relai buluh, adalah alat yang akan terpengaruh medan magnet dan akan memberikan perubahan kondisi pada keluaran. Seperti layaknya saklar dua kondisi (on/off) yang digerakkan oleh adanya medan magnet di sekitarnya. Biasanya sensor ini dikemas dalam bentuk kemasan yang hampa dan bebas dari debu, kelembapan, asap ataupun uap. Sensor magnet ditunjukan pada Gambar 4.

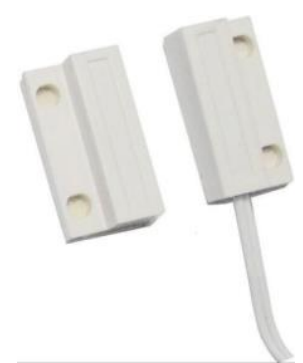

Gambar 4. Sensor magnet

5. SIM 800L, GSM atau GPRS module untuk Arduino, Raspberry Pi. Dapat digunakan untuk mengirim SMS, calling, transfer data melalui GPRS \& fungsi DTMF [10]. SIM 800L support Quad-band 850/900/1800/1900MHz. Dilengkapi juga fungsi Bluetooth, FM \& Embedded AT. SIM 800L GPRS GPS yang digunakan dapat dilihat pada Gambar 5 . 


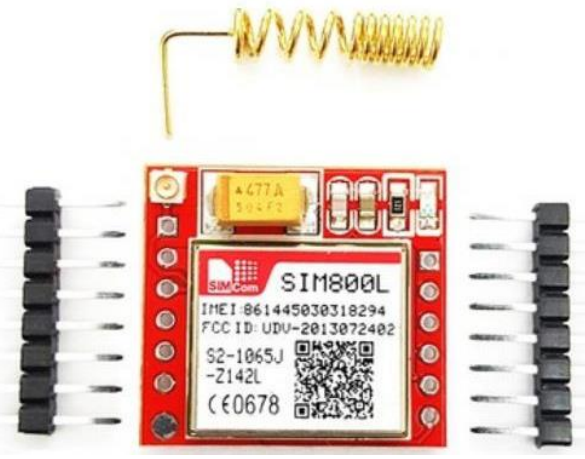

Gambar 5. SIM 800L GPRS GPS

6. Modul LM2596, digunakan untuk menurunkan tegangan DC maksimal hingga $3 \mathrm{~A}$ dengan range DC 3.2V-46V dengan selisih minimum input - output 1.5V DC. Modul LM2596 ditunjukkan pada Gambar 6.

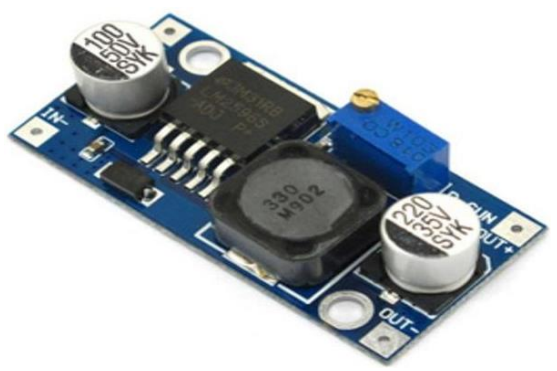

Gambar 6. Modul LM2596

B. Tahapan Penelitian

Tahapan penelitian yang dilakukan mencakup beberapa tahapan, yakni sebagai berikut:

1. Perancangan blok diagram, dimaksudkan untuk menjelaskan prinsip kerja alat. Adapun blok diagram sistem ini dapat dilihat pada Gambar 7.

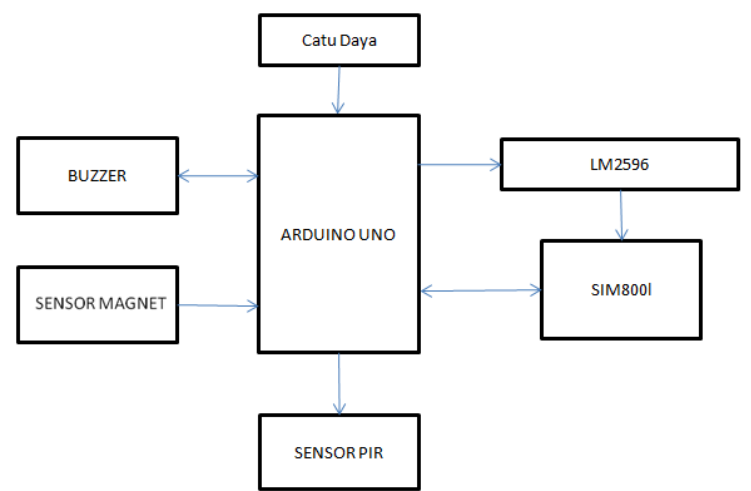

Gambar 7. Blok diagram alat

Dari blok diagram dapat dijelaskan fungsi masing-masing blok sistem, sebagai berikut:

- Catu daya berfungsi sebagai sumber listrik pada alat ini, karena pada setiap rangkaian membutuhkan suplai dalam bentuk tegangan DC.

- LM2596 berfungsi sebagai penurun tegangan atau step down yang dibutuhkan oleh sim 800L
- $\quad$ SIM 800L berfungsi sebagai pengirim notifikasi ke handphone

- Mikrokontroler Arduino UNO sebagai pengontrol dari keseluruhan sistem yang akan mengatur kinerja dari sistem pengatur alat.

- $\quad$ Sensor PIR berfungsi sebagai pendeteksi bahwa ada pergerakan di dalam ruangan.

- Buzzer digunakan sebagai indikator peringatan bahwa ada sebuah pergerakan didalam ruangan maka buzzer akan aktif.

- Sensor magnet digunakan sebagai pendeteksi pada sebuah pintu pada kondisi terbuka dan tertutup.

2. Perancangan rangkaian catu daya, dibutuhkan untuk mensuplai rangkaian. Karena hanya mikrokontroler yang memerlukan sumber tegangan langsung, sedangkan komponen lain mengambil tegangan dari mikrokontroler, catu daya yang diberikan hanya $5 \mathrm{~V}$ DC melalui port USB Arduino UNO.

3. Perancangan rangkaian sensor PIR, digunakan sebagai pendeteksi pergerakan dalam ruangan pribadi dimana hubungan sensor PIR dengan Arduino yaitu pin 5v Arduino terhubung dengan pin sensor PIR vcc dimana sebagai konsumsi daya dan ground ke ground sedangkan output sensor PIR terhubung ke pin 2 dari Arduino sebagai data yang akan diolah oleh Arduino apabila sensor PIR membaca adanya pergerakan di dalam sebuah ruangan. Berikut rangkaian sensor PIR pada Arduino UNO ditunjukkan pada Gambar 8 .

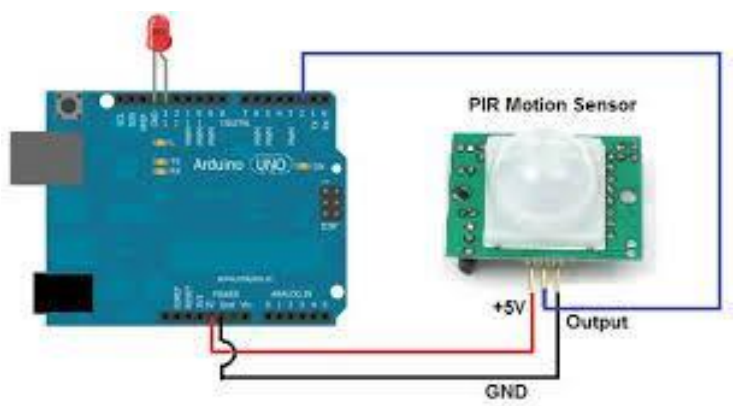

Gambar 8. Rangkaian sensor PIR

4. Perancangan rangakaian SIM 800L, sebuah komponen yang mempunyai sebuah fungsi yaitu untuk mengirimkan informasi ke pada penerima yang telah ditentukan, dan membutuhkan penyuplai tegangan sebesar kurang dari 5v disini digunakan DC converter yang berfungsi sebagai penyuplai tegangan yang dibutuhkan oleh SIM 800L. Tegangan yang diambil dari DC converter berasal dari 5v Arduino dan diatur di DC converter sehingga memenuhi tegangan yang dibutuhkan dari SIM 800L, ada 4 buah pin yang dipakai antara lain vcc SIM 800L yang terhubung pada pin output + dari DC converter dan ground ke output - dari DC converter dan pin RX SIM 800L ke pin 7 dari Arduino dan TX SIM 800L ke pin 8 dari Arduino dimana kedua pin ini sebagai pengirim sekaligus penerima perintah maupun informasi. Berikut rangkaian sim $800 \mathrm{~L}$ pada Arduino UNO yang dapat dilihat pada Gambar 9 . 


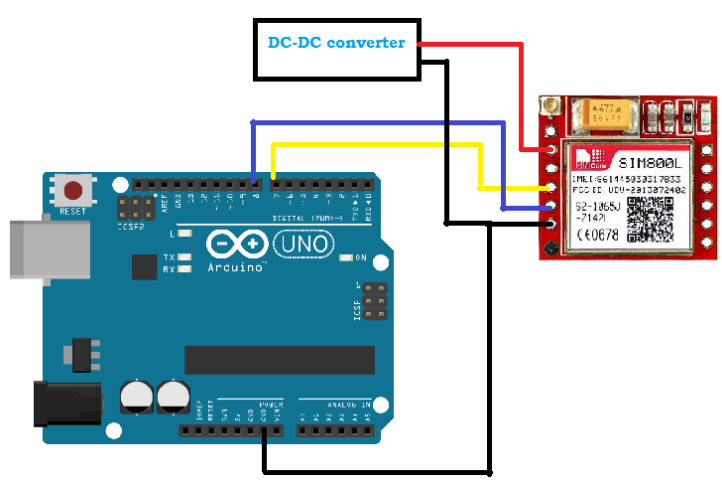

Gambar 9. Rangkaian SIM 800L

5. Perancangan rangkaian buzzer, digunakan sebagai indikator dari sensor PIR jika sensor PIR mendapatkan sebuah pergerakan dari ruangan tersebut, ada dua pin buzzer satu pin vcc terhubung ke pin 5v dari pada Arduino sedangkan pin satunya terhubung ke pin 2 Arduino sebagai penghubung dari sensor PIR. Berikut rangkaian buzzer pada Arduino UNO yang ditunjukkan pada Gambar 10 .

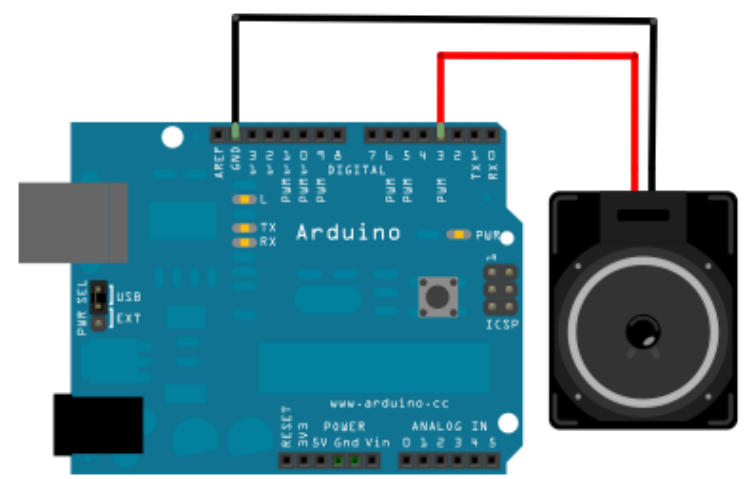

Gambar 10. Rangkaian buzzer

6. Perancangan rangkaian sensor magnet, berfungsi sebagai pengamanan pintu pada saat kondisi pintu terbuka dan tertutup. Sensor magnet terdiri dari 2 kabel yang terdiri dari ground dan data. Pada rangkaian ini data pada sensor PIR terhubung ke pin 4 di Arduino. Berikut rangkaian sensor magnet pada Arduino UNO yang dapat dilihat pada Gambar 11 .

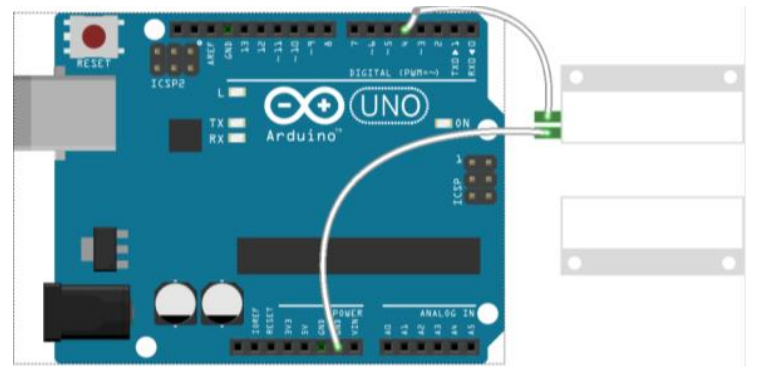

Gambar 11. Rangkaian sensor magnet

7. Perancangan rangkaian secara keseluruhan, bagianbagian port untuk memasang bagian komponen yang dibutuhkan. Terdapat 14 port output yaitu port 1 (RX), 2 (TX), 3, 4, 5, 6, 7, 8, 9, 10, 11, 12, 13 dan 6 port analog input yaitu A0, A1, A2, A3, A4, dan A5.
Pemasangan komponen pada mikrokontroler dapat dilihat pada Gambar 12 .

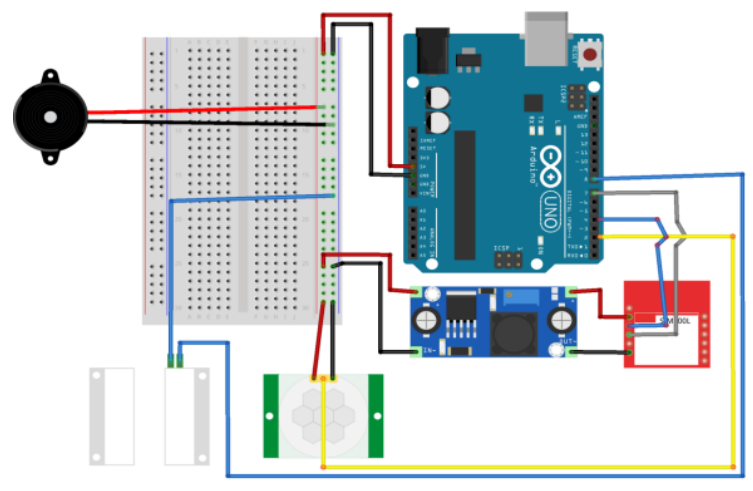

Gambar 12. Rangkaian keseluruhan alat

8. Perancangan perangkat lunak, dimulai setelah perancangan rangkaian-rangkaian yang dibutuhkan. Untuk penyusunan perangkat lunak yang mengendalikan peralatan tersebut, bahasa pemrograman yang digunakan adalah bahasa $\mathrm{C}$. Proses pemrograman diawali dengan menulis program sumber (source code). Source code kemudian di-compile dan akan menghasilkan kodekode yang dapat dimengerti oleh mikrokontroler (format *.ino). File dengan ekstensi *.ino ini yang nantinya akan di-download ke mikrokontroler.

\section{Hasil dan Pembahasan}

Sistem keamanan pada ruangan pribadi ini terdiri dari 1 buah sensor magnet, sensor PIR, buzzer, SIM 800L, dan 1 buah mikrokontroler Arduino UNO. Sensor magnet berfungsi untuk mengetahui bahwa keadaan pintu dalam kondisi terbuka, sensor PIR berfungsi sebagai pendeteksi pergerakan yang ada di dalam ruangan, SIM 800L berfungsi sebagai pengirim informasi kepada pemilik ruangan apa bila sensor pir mendapatkan sebuah pergerakan di dalam ruangan, buzzer berfungsi sebagai alarm saat sensor PIR mendapatkan adanya pergerakan di dalam ruangan dan mikrokontroler Arduino sebagai otak dan pemroses keseluruhan komponen sistem. Dalam pembuatan sistem ini digunakan perangkat lunak Arduino IDE pada sistem operasi Windows 10 Profesional 64 bit. Tampilan dari alat yang dibangun dapat dilihat pada Gambar 13 dan Gambar 14. 


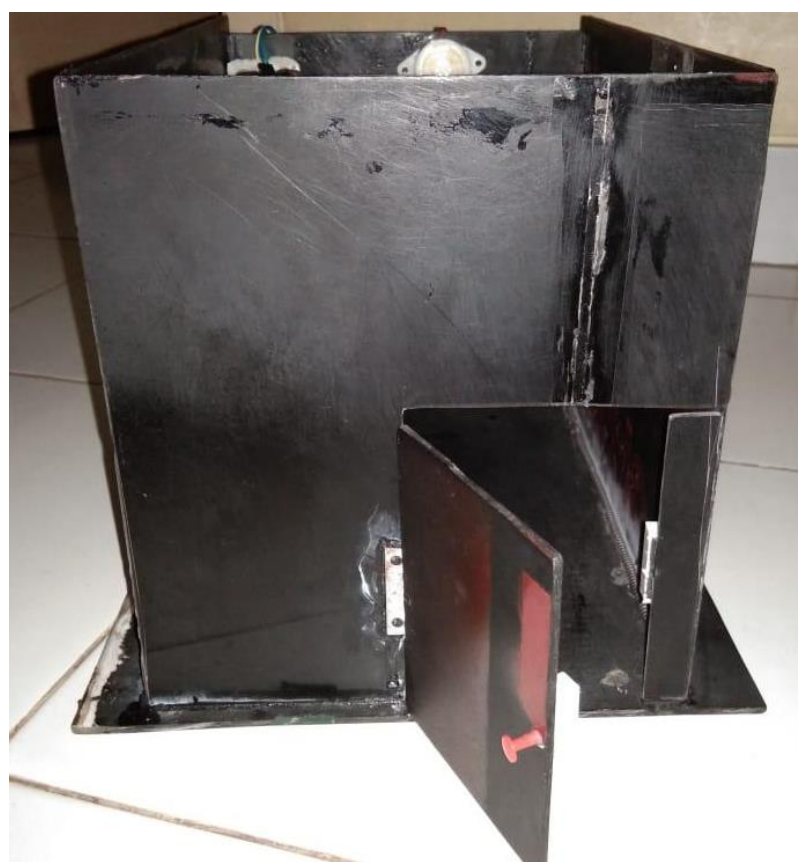

Gambar 13. Alat tampak depan

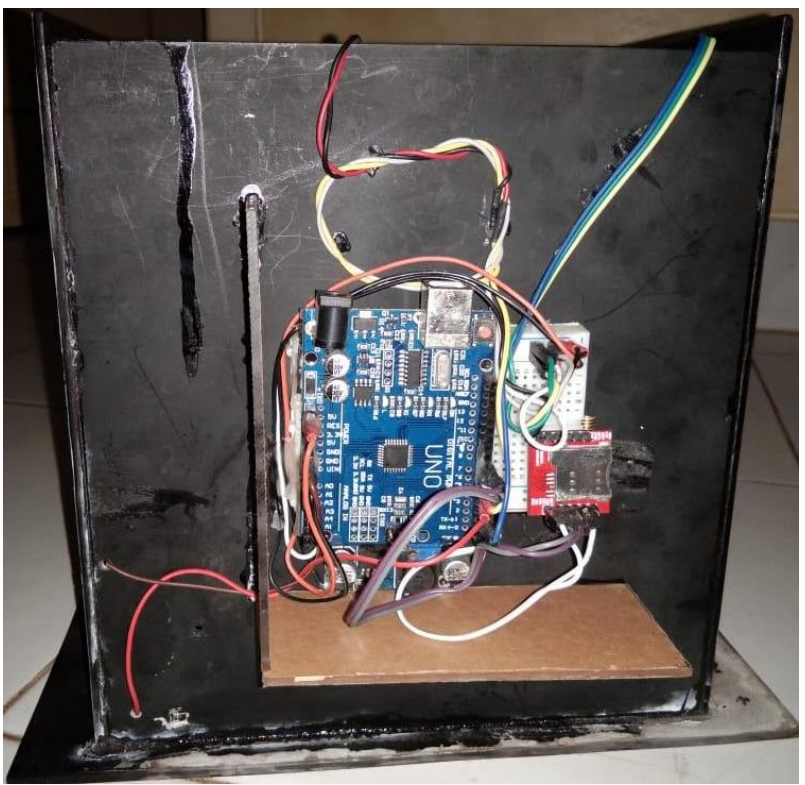

Gambar 14. Alat tampak belakang

\section{A. Alur Proses}

Alat keamanan pada ruangan pribadi ini berguna untuk mengetahui apakah ada seseorang yang masuk ke ruangan pribadi. Cara kerja pada sistem ini adalah ketika mikrokontroler mendapat perintah dari program yang sudah dibuat kemudian menginstruksikan ke sensor PIR untuk mengetahui ada atau tidak adanya sebuah pergerakan pada ruangan, setelah sensor PIR mendapatkan sebuah pergerakan pada ruangan maka buzzer akan aktif dan SIM 800L akan memberikan informasi ke handphone, begitu pula dengan sensor magnet yang terpasang pada pintu jika pintu dalam keadaan terbuka maka SIM 800L akan mengirimkan informasi ke handphone bahwa pintu ruangan dalm keadaan terbuka.

Alur proses dalam pengoperasian alat ini agar dapat bekerja adalah sebagai berikut:

1. Menghubungkan alat ke catu daya untuk menghidupkan sistem.

2. Mengatur sensor PIR agar mendapatkan posisi yang sesuai.

3. Men-download-kan program pada hardware arduino (jika program belum di-download-kan).

4. SIM 800L akan mengirimkan informasi sebuah kondisi kepada pemilik ruangan apabila sensor PIR dan sensor mendapat kan sebuah kondisi yang berbeda pada posisi awal.

5. Buzzer akan aktif apabila sensor PIR mendapatkan sebuah kondisi pergerakan yang ada dalam ruangan.

B. Pengujian

Setelah dilakukan pembuatan sistem keamanan pada ruangan pribadi dengan mikrokontroler Arduino dan SMS gateway, selanjutnya dilakukan pengujian rangkaian alat. Pengujian alat ini bertujuan untuk untuk mengetahui apakah alat yang dibuat sesuai dengan yang telah direncanakan sebelumnya. Pada pengujian alat ini, dilakukan terhadap masing-masing komponen yang digunakan pada alat. Pengujian yang dilakukan pada alat ini adalah sebagai berikut:

1. Pengujian catu daya, dilakukan untuk mengetahui apakan semua komponen yang terhubung dapat menerima sumber tegangan secara baik dan menghindari perkabelan yang buruk atau terputus sehingga tidak ada salah satu komponen yang tidak menyala akibat tidak terpasok sumber tegangannya. Karna semua komponen mengambil daya dari mikrokontroler maka pengujian catu daya cukup dengan menghubungkan mikrokontroler pada sumber tegangan seperti adaptor, powerbank, ataupun laptop. Dapat dilihat bahwa lampu indikator hidup pada Gambar 15, yang artinya catu daya berfungsi dengan baik.

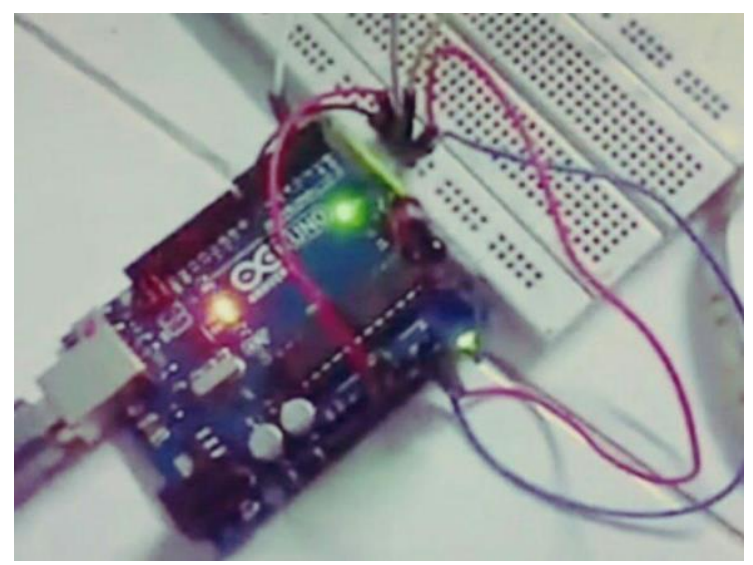

Gambar 15. Pengujian catu daya

2. Pengujian mikrokontroler, dilakukan pada mikrokontroler Arduino UNO yang mana bagian ini merupakan pusat pengolahan data pada sistem keamanan ruangan ini. Pengujian yang dilakukan ini merupakan pengujian dengan program mikrokontroler Arduino dan mengirimkan perintah ke SIM 800L untuk mengirim SMS pada nomor tujuan. 
3. Pengujian sensor magnet, sebagai sistem keamanan yang terpasang pada pintu, maka sensor magnet harus dilakukan pengujian agar sistem dapat bekerja secara optimal, disini dibungkan sensor magnet ke Arduino yang dimana sensor magnet akan mengirim data yang akan di proses oleh mikrokontroler dan data tersebut akan dijadikan informasi yang akan dikirim oleh SIM 800L dengan SMS gateway. Pada Gambar 16 dapat dillihat bahwa sensor magnet mendapatkan data dan data tersebut diolah oleh sim 800L dan diolah menjadi SMS gateway.

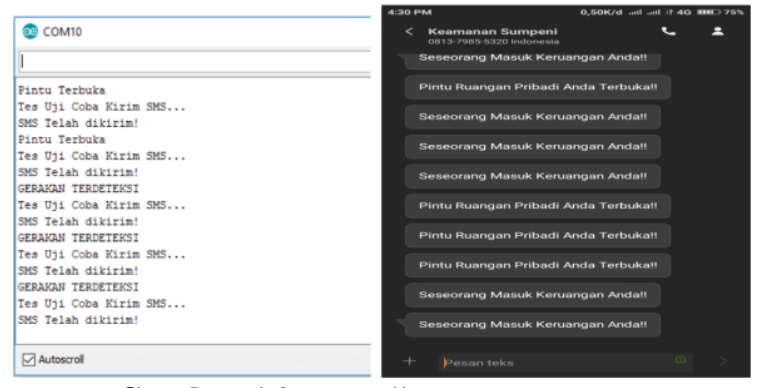

Gambar 16. Pengujian sensor magnet

4. Pengujian sensor PIR, dilakukan untuk mengetahui seberapa jarak efisien yang dapat dibaca oleh sensor PIR, disini digunakan komponen tambahan berupa buzzer agar dapat diketahui jarak efisien pada sensor pir. Cara yang dilakukan adalah melakukan pengukuran jarak dengan alat ukur meteran dan manusia dengan jarak 6 meter saja. Berikut adalah hasil dari pengujian jarak efisien dari sensor PIR dapat dilihat pada Tabel 1.

Tabel 1. Hasil pengujian sensor PIR

\begin{tabular}{cccc}
\hline No & Jarak & Data 1 & Data 2 \\
\hline 1 & $1 \mathrm{~m}$ & Terdeteksi & Terdeteksi \\
2 & $2 \mathrm{~m}$ & Terdeteksi & Terdeteksi \\
3 & $3 \mathrm{~m}$ & Terdeteksi & Terdeteksi \\
4 & $3.5 \mathrm{~m}$ & Terdeteksi & Terdeteksi \\
5 & $4 \mathrm{~m}$ & Terdeteksi & Terdeteksi \\
6 & $4.5 \mathrm{~m}$ & Terdeteksi & Terdeteksi \\
7 & $4.9 \mathrm{~m}$ & Tidak & Terdeteksi \\
8 & $5 \mathrm{~m}$ & Terdeteksi & Terdeteksi \\
\hline
\end{tabular}

Dari data yang telah diuji maka dapat diketahui bahwa adanya data selisih pada sensor PIR dimana dapat terjadinya salah pembacan data dan masih bisa dikatakan dalam toleransi kesalahan, sehingga sensor pir pada sistem ini berfungsi dengan baik.

5. Pengujian SIM 8001, dimana komponen tersebut berfungsi sebagai pengirim notifikasi atau informasi kepada nomor yang sudah ditentukan. SIM 800L pada alat yang diberikan mengirimkan notifikasi apabila sensor magnet maupun sensor PIR mendapatkan sebuah data yang diterima maka kedua sensor akan mengirimkan data tersebut ke SIM 800L dan diolah menjadi informasi berupa SMS yang dikirimkan kepada pemilik ruangan tersebut. Berikut adalah hasil dari pengujian SIM 800L yang ditunjukkan pada Gambar 17.

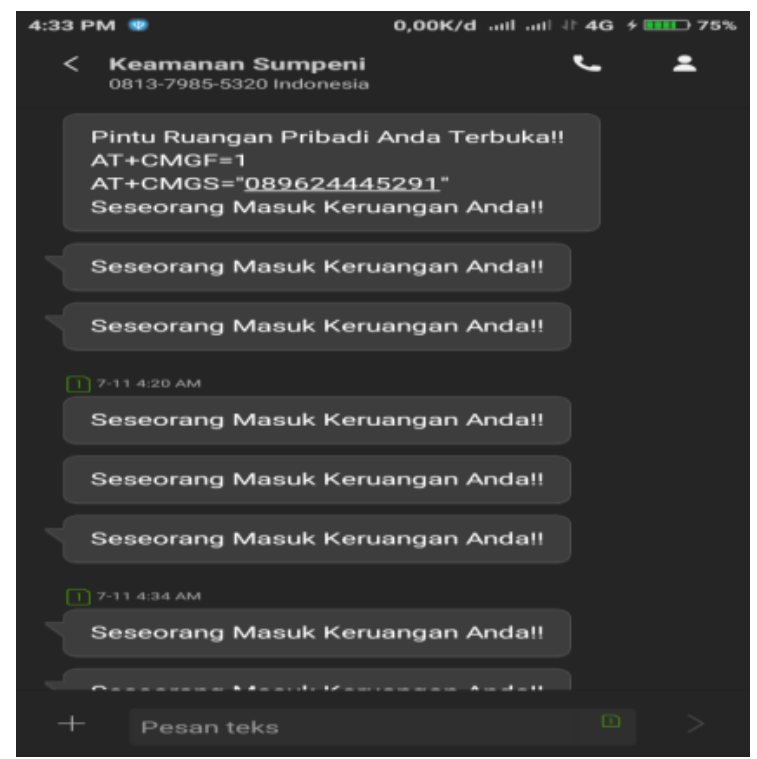

Gambar 17. Pengujian SIM 800L

Dari Gambar 17 bahwa SIM 800L dapat berfungsi berfungsi secara optimal pada alat yang dibuat.

\section{Kesimpulan dan Saran}

Dari hasil pengujian yang telah dilakukan maka dapat ditarik kesimpulan bahwa: 1) Komponen yang digunakan dalam pembuatan alat berupa Arduino UNO, sensor magnet, sensor PIR, SIM 800L, buzzer, dan akrilik yang digunakan sebagai miniatur kerangka dari ruangan dan dapat berfungsi dengan baik; 2) Pembuatan alat keamanan ruangan pribadi menggunakan sensor magnet yang diletakan di bagian pintu ruangan yang dimana sensor magnet terhubung ke mikrokontroler serta dapat menginformasikan melalui SIM 800L apabila sensor magnet mendapatkan data bahwa pintu terbuka; 3) Sensor PIR dapat berfungsi sebagai pendeteksi pergerakan pada seseorang yang ada didalam ruangan pribadi dengan jarak akurat sampai dengan 5 meter; 4) SIM 800L berfungsi sebagai pengirim dari keadaan yang ada diruangan pribadi apakah ada sebuah pergerakan atau pintu dalam kondisi terbuka; 5) Ketika sensor PIR dan sensor magnet mendapat kan kondisi maka SIM 800L akan aktif dan mengirimkan informasi ke pemilik ruangan pribadi tersebut.

Berdasarkan percobaan yang telah dilakukan dan hasil yang diperoleh, masih terdapat kekurangan pada sistem alat ini, maka dapat diambil beberapa saran yang dapat dikembangkan, diantaranya: 1) Agar dapat ditambahkan kamera supaya dapat mengetahui identitas seseorang yang masuk ke dalam ruangan; 2) Ditambahkannya pengontrolan komunikasi pada SMS 
gateway agar dapat dikontrol dan mengetahui bahwa yang berada di dalam ruangan tersebut adalah si pemilik ruangan; 3) Ditambahkannya komunikasi pada SMS gateway, pengontrolan ini berupa untuk mengaktifkan dan mematikan alat pada saat pemilik masuk ke dalam ruang.

\section{Daftar Pustaka}

[1] A. I. Yusuf, S. Samsugi, and F. Trisnawati, "Sistem Pengaman Pintu Otomatis Dengan Mikrokontroler Arduino Dan Module RF Remote," J. Ilm. Mhs. Kendali dan List., vol. 1, no. 1, pp. 1-6, 2020.

[2] A. Nurkholis, A. Riyantomo and M. Tafrikan, "Sistem pakar penyakit lambung menggunakan metode forward chaining," Majalah Ilmiah Momentum, vol. 13, no. 1, 2017.

[3] A. Nurkholis and I. S. Sitanggang, "Optimalisasi model prediksi kesesuaian lahan kelapa sawit menggunakan algoritme pohon keputusan spasial," $J$. Teknol. dan Sist. Komput., vol. 8, no. 3, pp. 192-200, 2020, doi: 10.14710/jtsiskom.2020.13657.

[4] A. Nurkholis and I. S. Sitanggang, "A spatial analysis of soybean land suitability using spatial decision tree algorithm," in Sixth International Symposium on LAPAN-IPB Satellite, Dec. 2019, no. December, p. 113720I, doi: 10.1117/12.2541555.
[5] A. Gifson, "Sistem Pemantau Ruang Jarak jauh dengan Sensor Passive Infrared berbasis Mikrokontroler AT89S52," TELKOMNIKA, vol. 7, no. 3, p. 201, 2009.

[6] R. Suzuki, "Monitoring Daily Living Activities of Elderly People in a Nursing Home Using an Infrared Motion-Detection System," Telemedicine Journal \& Health, vol 12, April 2006.

[7] Y. Rahmanto, A. Rifaini, S. Samsugi, and S. D. Riskiono, "Sistem Monitoring pH Air Pada Aquaponik Menggunakan Mikrokontroler Arduino UNO," J. Teknol. dan Sist. Tertanam, vol. 1, no. 1, pp. 23-28, 2020.

[8] S. Samsugi, Z. Mardiyansyah, and A. Nurkholis, "Sistem Pengontrol Irigasi Otomatis Menggunakan Mikrokontroler Arduino UNO," J. Teknol. dan Sist. Tertanam, vol. 1, no. 1, pp. 17-22, 2020.

[9] A. Pangestu, A. Z. Iftikhor, Damayanti, and M. Bakri, "Sistem Rumah Cerdas Berbasis IoT Dengan Mikrokontroler NodeMCU dan Aplikasi Telegram," J. Tek. dan Sist. Komput., vol. 1, no. 1, pp. 8-14, 2020.

[10] A. S. Puspaningrum, F. Firdaus, I. Ahmad, and H. Anggono, "Perancangan Alat Deteksi Kebocoran Gas Pada Perangkat Mobile Android Dengan Sensor Mq2," J. Teknol. dan Sist. Tertanam, vol. 1, no. 1, pp. 1$10,2020$. 